\title{
Document Management in Project Development
}

\author{
$\mathrm{Xin} \mathrm{Xu}^{1, \mathrm{a}, *}$ \\ ${ }^{1}$ Sichuan Institute of Solid State Circuits, China Electronics Technology Group Corp., \\ Chongqing 400060, P. R. China \\ a shenlandehai@126.com \\ *corresponding author
}

Keywords: Document Management, Optimize Flow, Classification Methods.

\begin{abstract}
This paper firstly introduces the importance of document management, the composition of the document is classified, then introduces the theory of document management, analyses all stages of document management in our country, and further introduces the function of enterprise document management, finally, some suggestions are put forward to optimize the document flow.
\end{abstract}

\section{Introduction}

With the advent of the era of knowledge economy, knowledge has become the first production factor. How to effectively exploit and manage the knowledge resources of enterprises has become the key to the success of enterprises. Among many knowledge resources in enterprises, the document is one of the most important ones. At present, the document management of the enterprise has not been able to effectively play its role. As a result, a large amount of knowledge resources contained in these documents have not been effectively developed and utilized. Many corporate knowledge resources were wasted. Therefore, how to conduct a scientific and systematic management of enterprise documents has become an indispensable link in business management in the era of knowledge-based economy.

At present, many enterprises have realized that document management has a significant impact on business operations and has invested a great deal of manpower, material resources and financial resources in document management. However, the effectiveness of document management is not significant. There are still many problems in document management, such as the storage of mass documents, slow searching, inability to effectively track the entire process of document creation, delivery and storage in the enterprise and the security control of documents. The problem of appeals is the superficial phenomenon existing in the management of enterprise documents, but its essence is caused by the problems of the enterprise in the deeper level of system, concept and thought, that is, ignoring the knowledge attributes of documents and retaining the use of document resources in Fixed processes, systems, can not dig deep potential value of document resources, passive management of a small number of enterprises

Dominant knowledge, however, excludes a large amount of tacit knowledge in the enterprise from the scope of document management.

\section{The Classification of Industry Documents}

Business documents in accordance with different principles have different classification methods to grasp the different types of corporate documents features that help to take targeted measures in document management.

(1) Paper documents and electronic documents According to the document bearing the form, storage, the document is divided into paper documents and electronic documents. Electronic documents include both WORD, PDF, TXT and other documents, as well as images, audio, video and other forms of multimedia-rich documents. The characteristics of electronic documents and paper documents: In terms of fluidity, electronic documents outperform paper documents, 
electronic documents faster, and save unnecessary printing costs, but for some need to sign the importance of the importance of business processes, electronic Documents easily lead to controversy due to unclear division of labor. In terms of security, paper documents are superior to electronic documents, electronic documents are easily affected by computer hardware and software environment, power outages, hacking and other issues of shadow paper as long as the sound regulatory process, the general safety is more reliable.

(2) Current documents, semi-current documents and non-current documents This is the most typical classification of the traditional document movement process, which is divided according to the characteristics of each stage of the document life cycle. The main function of the current document is circulation, so its storage method to take electronic documents as well; and semicurrent and non-current documents are mainly used to save the records and to be found, should adopt the electronic document and paper document management, paper, Mainly to save and retain the quality of the document the role of the end, because the safety of paper documents, and electronic documents mainly play a quick query, download, improve the efficiency of document management.

(3) Knowledge documents and business documents According to the different business categories, business documents can be divided into knowledge documents and business documents. Business documents mainly for the business of the regular business, that is, a mature system has been formed, norms, such knowledge is low, such as log files, business rules, administrative records and other reports; knowledge of the document mainly for enterprise technology, The R \& D department's business is formed in the core activities that are directly related to the business development. For example, product design specifications, feasibility studies, and annual financial statements of the enterprise, employees who correspond to the knowledge documents tend to master the key technologies of the enterprise, the education background is relatively high. Compared with the transactional documents, knowledge documents are the resources that enterprises need to focus on management and development. With the advent of the information era and knowledge era, the importance of electronic documents and knowledge documents will gradually appear. Effective management of these two types of documents can bring long-term benefits to the enterprise.

\section{Research Status of File Management}

Overall, the relevant research work on document management at home and abroad mainly focuses on document integration management, document life cycle, document management system and related technologies.

(1) Research on Document Integration There are a large number of documents and reports at home and abroad to study the integrated document management. The integration of documents means that the two management systems which are relatively independent and have the same many aspects of document processing and file management are grouped together into a unified scientific system and the documents from the time of formation to the archives and archives management All aspects of the formation of a scientific system. The three different stages of document integration research experience: the embryonic stage, the slow development stage and the rapid development stage, the document and the archives merge and then the separation, and now they begin the process of integration again.

(2) Research on Document Life Cycle In the mid-20th century, the number of documents in the organization increased sharply. The concept of "document life cycle" was firstly proposed by American archivist Phillip Brooks. It refers to the concept of document life cycle from the point of creation, circulation and utilization until the destruction or Permanent preservation of the entire movement process. On the document life cycle, the previous literature mainly focused on two aspects. The first is to study the application of document cycle theory in electronic documents. The second is to combine document life cycle theory with enterprise document management, especially document integration management.

(3) Research on Document Management System As for the design and application of document management system, there are a large number of documents, reports and related patents at home 
and abroad related to this content. This research mainly focuses on the combination of IT technology and document management to design and research a document management system for enterprises or certain industries in order to improve the efficiency of document management and realize the informationization of document management.

\section{Connotation and Development of Industry Document Management}

Document management has experienced a long period of development in our country. With the advent of the information age and the knowledge age, some ideas, methods and tools of document management have undergone major changes. The development of enterprise document management in our country has generally experienced the following three stages.

(1) Substantive management stage: at this stage, as the computer technology has not been popularized, the document management mainly carries out the entity management of the paper documents and manually generates, uses, classifies, archives or destroys the documents by hand. The materialization stage the focus of document management is cataloging and archiving. The documents are stored in the filing cabinet according to the compiled catalog card orderly. The document retrieval is based on the corresponding cabinet, volume and periodicals and is manually retrieved by the administrator in charge of archiving, The retrieval efficiency is low, and the development and utilization of document value is very few. The most important function of materialized document management is to save the historical records. The document management in this stage is similar to the file management.

(2) Information Management Stage: the tasks, objects and tools of enterprise document management in this stage have undergone great changes. Enterprise production enters the stage of informationization, a large number of electronic documents produced, document management by the traditional manual management turned to the use of computer technology for information management, the use of document management system so that employees in different regions to facilitate the exchange of information and sharing of documents so that the document Value has been partially reflected. The key of informationization stage lies in the use of information technology to realize the retrieval, retrieval, upload and storage of documents, and to solve the problem of manual management inefficiency in the substantive stage. However, the knowledge in the documents has not been given enough attention, mainly Management of business documents of the class, the development of knowledge of the document is weak, resulting in information overload and lack of knowledge situation.

(3) The stage of knowledge management: this stage with the advent of the era of knowledgebased economy, companies from the perspective of knowledge management to re-examine the document management, the document is defined as the knowledge resources of enterprises in the document management process focus on knowledge mining and development The purpose of knowledge document management stage is to realize the knowledge value of documents, to make tacit knowledge explicit and to accumulate and create knowledge. The tools and methods used in this phase have also changed. Information technology and knowledge management tools such as artificial intelligence, text mining and knowledge warehouse are combined to make statistical analysis and deduction and induction of document knowledge so as to realize the development and utilization of document knowledge.

\section{Document Management Optimization}

Document management is a record of work trajectory, description of work ideas, laying the foundation for the work of the carrier. Document may be shaped into a statutory record of information is the organization in the management process left traces. Excellent document management, as conducive to the sharing and accumulation of knowledge and skills of the company, is conducive to the efficient delivery of managers' will, and is conducive to improve organizational management efficiency. Document management must be built on the premise of improving efficiency rather than managing it. Therefore, the first principle of document management design is 
to improve the level of document management and reduce the number of documents management of internal friction. Excellent document management should have the following principles:

(1) Normative features. The so-called normative documents should establish a unified way of expression, the establishment of standards the model. For example, a document should contain the purpose, scope, responsibility, content, records, attached a few units. Without these definitions, a myriad of expressions will follow. These chaos the expression will make the authority of the organization's internal document management system file be questioned, and thus not for document management followed by. Documents should be unified management and classification of norms, such as what is the standard, what is the regulation, what is the operational guidance, what is the process, what is the letter and so on. Document definition is not clear, it is easy to produce health management confusion and language system confusion, but also in the event can not define what kind of event to use what process to describe.

(2) The characteristics of consistency. Consistency mainly refers to the consistency of the contents of the management documents, such as organizational constraints an incident, if many of the documents are talking about a problem, are each regulating the standard of a problem, from their own describe the management behavior from an angle, without a uniform rule, will lead to perplexed implementers.

(3) The completeness of document management. From a management perspective, the document needs to establish a traceability mechanism, for example, the history of a document creation, update and deletion, the alternation of old and new documents, version updates, and the like.

(4) Timeliness of document management. Timeliness is a key requirement for document management, as it is largely shadowing ring the progress of the project. When events in the project change, the document should also be updated as needed real-time, in reverse reflect the current state.

(5) Document management information sharing, that is, communication mechanisms. The most prominent issue in project management is ditch through the problem, because the project management failed to communicate a lot of cases of failure, the same document management communication mechanism it is also very important, it will affect the quality of document management. in summary, document management optimization in the need to comply with the norms, consistent, complete, time-sharing and optimization principles such as sharing can really improve the document management, play a role in the right remedy.

\section{Conclusion}

This paper first introduces the importance of document management, The composition of the document has been classified, then introduced the theory of document management, analysis of all stages of document management in our country. introduced the function of enterprise document management, Finally, some suggestions are put forward to optimize the document flow..

\section{References}

[1] Plessis M. Knowledge Management in Business and Customer Relationship Management: South African Case Study Findings[J]. Information Management, 2004: 73-86..

[2] Desmond J P. Knowledge Base Supports Online Performance Marketing[J]. Software Magazine, 2001(1):25-30.

[3] Xueying Zhang. Concept Integration of Document Databases Using Different Indexing Languages [J]. Information Processing \& Management, 2006,42(1) :121-135.

[4] Ham B, Emati N. Knowledge Warehouse: an Arch Integration of Knowledge Management, Decision Support, Artificial Intelligence and Data Warehousing[J]. Decision Support System, 2002, 143-161. 